\title{
Synaptic Potentials in the Central Terminals of Locust Proprioceptive Afferents Generated by Other Afferents from the Same Sense Organ
}

\author{
Malcolm Burrows and Gilles Laurent \\ Division of Biology, California Institute of Technology, Pasadena, California 91125
}

\begin{abstract}
Afferent neurons from a proprioceptor [the femoral chordotonal organ (FCO)] at the femoro-tibial joint of a locust hindleg carry patterns of spikes to the CNS in which information is coded about the positions and movements of the tibia. Intracellular recordings from the afferents of this organ as they enter the CNS reveal spikes and depolarizing postsynaptic potentials (PSPs) during voluntary or imposed movements of the joint. Some of these PSPs are generated as a result of spikes in other FCO afferents, and can be evoked experimentally by electrical stimulation of the nerve from the organ. One afferent does not appear to synapse directly on another, but instead activates reliable pathways involving other central neurons.
\end{abstract}

Current clamping of individual afferents in isolated ganglia shows that the PSPs are increased in amplitude by hyperpolarizing currents injected into an afferent, and decreased by depolarizing ones. They reverse at about $-68 \mathrm{mV}(n=$ 5). At the normal resting potential of the afferents, $-72 \mathrm{mV}$ $( \pm 0.42$ SE, $n=57$ ), the PSPs are therefore depolarizing, and are associated with an increased conductance of the membrane. The changes in membrane potential and conductances associated with the PSPs can be mimicked by pressure injection of GABA into the regions of neuropil that contain the terminals of the afferents. The potential evoked by GABA is associated with an increased conductance of the membrane and reverses at the same potential as the PSPs. GABA also reduces the PSPs evoked in the terminals, either by movements of the FCO or by electrical stimulation of its nerve. The PSPs and the effects of the GABA-evoked potentials are mimicked by the GABA agonist muscimol. The PSPs are blocked reversibly by picrotoxin.

The PSPs and the GABA-evoked potentials both alter the excitability of an afferent terminal by reducing the ability of the membrane to support an action potential. It is suggested that the PSPs are depolarizing, inhibitory potentials generated in the terminals of the afferents by central neurons that release GABA, and that their role is to change the efficacy of the afferent spikes at their first output synapses in the CNS. These interactions could form a graded, gain control

\footnotetext{
Received Apr. 13, 1992; revised July 24, 1992; accepted Aug. 21, 1992.

This work was supported by a grant from the Human Frontier Science Program (to M.B. and G.L.) and by NIH Grants 16058 (to M.B.) and NS29194 (to G.L.). M.B. was the Wiersma Visiting Professor of Biology during the course of this work. G.L. is a Searle and a McKnight Scholar, and an Alfred P. Sloan Fellow. We thank our colleagues and two anonymous referees for their constructive comments.

Correspondence should be addressed to Malcolm Burrows, Department of Zoology, University of Cambridge, Downing Street, Cambridge CB2 3EJ, UK.

Copyright @ 1993 Society for Neuroscience $0270-6474 / 93 / 130808-12 \$ 05.00 / 0$
}

mechanlsm for synaptic transmission at the afferent output synapses that is directly dependent on the features of the mechanical movements of the joint.

[Key words: presynaptic inhibition, mechanosensory processing, GABA, locomotion, gain control, proprioception]

There can be no safe expectation that the same pattern of sensory spikes from a proprioceptor or exteroceptor on a limb will always evoke the same motor response: the reliable pattern of spikes carried by the sensory axons may not be converted into a reliable sequence of events in postsynaptic neurons. In a walking animal, the sensory spikes will be superimposed on a rhythmic synaptic drive to many of the interneurons and motor neurons participating in the movement. In mammals (Gossard et al., 1991) and crustaceans (Sillar and Skorupski, 1986), the primary afferents themselves receive a synaptic input that is linked to the locomotory rhythm and is generated centrally. The mechanisms controlling the effectiveness of the sensory signals could therefore operate at two levels (Sillar, 1989), probably in parallel. First, the interneurons responsible for integrating the sensory signals could be modulated (Sillar and Roberts, 1988). Second, the changes could occur in the terminals of the sensory neurons themselves, thus altering the afferent spikes' effectiveness at producing changes in postsynaptic neurons.

Such presynaptic influences that could alter the ability of the spike to release transmitter from the terminals seem to be a common feature of most nervous systems. They are often associated with a depolarizing input to the terminals and a reduction in the amplitude of the spikes. In the cutaneous afferents of vertebrates, a synaptic input may be generated as a result of spikes in other cutaneous afferents that may increase spatial discrimination and limit excitation (Schmidt, 1971). Muscle afferents may also receive an input from afferents from other muscles that may result in an increased excitation to one set of motor neurons and a reduction to others (Rudomin et al., 1983; Rudomin, 1990). In crayfish, recordings near the central terminals of afferents from a proprioceptor at the coxo-basal joint of a walking leg reveal depolarizing synaptic potentials (Cattaert et al., 1990) that may contribute to the changes in reflex responsiveness that occur at different times during a rhythmic motor output from an isolated nervous system (El Manira et al., 1991). Much evidence suggests that postsynaptic potentials (PSPs) in the terminals of vertebrate afferents are caused by neurons that release GABA (Eccles et al., 1963; Davidoff, 1972; Nicoll and Alger, 1979). Similarly, injection of GABA into the neuropil close to the terminals of crayfish afferents evokes depolarizing potentials that are probably caused by an increase in 
chloride conductance (El Manira and Clarac, 1991; Cattaert et al., 1992).

In insects, electron microscopy shows that synapses are present on the terminals of many different types of sensory neurons (tarsal receptors, Geisert and Altner, 1974; wing stretch receptor, Altman et al., 1980; filiform hairs, Watson and Pflüger, 1984; Watson, 1990; campaniform sensilla, Watson and England, 1991; hair plates, Watson et al., 1991) and that some are immunoreactive to GABA (Watson and England, 1991; Watson et al., 1991). Physiological evidence also indicates that the processing of sensory signals is altered by synaptic inputs to the afferent terminals (Levine and Murphey, 1980; Blagburn and Sattelle, 1987; Boyan, 1988). These potentials reduce the amplitude of the afferent spikes and their synaptic effects on postsynaptic neurons (Blagburn and Sattelle, 1987).

An important proprioceptor in a leg of the locust is the femoral chordotonal organ (FCO). It is mechanically linked to the tendons of the only two muscles that operate this joint, the extensor and flexor tibiae muscles, such that it signals both extension and flexion of the femoro-tibial joint (Usherwood et al., 1968). No direct efferent control of this organ has been demonstrated. Information is coded in the approximately 90 sensory neurons (Matheson and Field, 1990) about the velocity, acceleration, and extent of movements of the femoro-tibial joint, and about the position of the tibia (Usherwood et al., 1968; Hofmann and Koch, 1985; Hofmann et al., 1985; Zill, 1985a; Matheson, 1990).

The afferents project to known regions of neuropil (Burrows, 1987; Schmitz et al., 1991; Matheson, 1992) where they synapse directly with motor neurons that innervate muscles moving the femoro-tibial joint (Burrows, 1987) and in parallel with nonspiking interneurons (Burrows et al., 1988), spiking local interneurons (Burrows, 1987, 1988; Büschges, 1989), and intersegmental interneurons (Laurent and Burrows, 1988). An input from this organ evokes resistance reflexes in muscles that move the femoro-tibial joint (Usherwood et al., 1968) and reflexes at the tibio-tarsal joint (Field and Rind, 1981). In an inactive animal the resistance reflexes can have stable components, in part because of the powerful monosynaptic connections that the afferents make with motor neurons, but show changes in responsiveness over time (Field and Burrows, 1982). In active animals, however, the reflex response to the same pattern of sensory signals can be more variable and can even be reversed in sign (Bässler, 1976, 1986; Zill, 1985b), suggesting that mechanisms must exist to change the reflex mode or gain.

The objectives here are to determine whether synaptic potentials are present in the terminals of these proprioceptive afferents, whether they are inhibitory or excitatory, whether they are mediated chemically, and if so, what the transmitter might be. It is shown that depolarizing, inhibitory synaptic potentials are common and arise as the result of spikes in other afferents from the same proprioceptor. They have a reversal potential just above resting potential and are mimicked by GABA. The synaptic and GABA-evoked potentials both reduce the excitability of the afferents.

\section{Materials and Methods}

Adult locusts, Schistocerca americana, of either sex were used from our crowded laboratory culture. Two types of preparation were used. First, a locust was mounted ventral surface uppermost with the coxa and femur of each leg restrained. The femur of the left hind leg was rotated so that its anterior surface was uppermost to allow access to the femoral chordotonal organ (FCO). The femoro-tibial angle was set at $90^{\circ}$ and then the FCO apodeme was grasped between the tips of fine forceps that were attached to a mechanical actuator. The apodeme could then be stretched to simulate a flexion movement of the femoro-tibial joint, or relaxed to simulate an extension, in a variety of waveforms produced by a function generator. Branch N5B1 of the main leg nerve (N5) was exposed just proximal to the point where it innervates the FCO and was placed on a pair of $100 \mu \mathrm{m}$ silver wire electrodes that were isolated from the surrounding saline by an oil-Vaseline mixture. These electrodes were used to record the pattern of sensory spikes evoked by an imposed movement of the FCO apodeme, or to stimulate the nerve and produce spikes in FCO afferents that traveled orthodromically toward the CNS. The metathoracic ganglion was then exposed in the thorax and stabilized on a wax-coated stainless steel platform. The thoracic cavity was perfused throughout an experiment with a constant flow of locust saline (140 mM NaCl, $5 \mathrm{~mm} \mathrm{KCl}, 5 \mathrm{~mm} \mathrm{CaCl}, 1 \mathrm{~mm} \mathrm{MgCl}$, and $4 \mathrm{mM} \mathrm{NAHCO}_{3}$ buffered to $\mathrm{pH} 7.2$ with $6.3 \mathrm{~mm} \mathrm{HEPES}$ ) at temperatures of $19-23^{\circ} \mathrm{C}$. This preparation was viable for $4-5 \mathrm{hr}$.

The second preparation was an isolated metathoracic ganglion. All peripheral nerves surrounding the meso- and metathoracic ganglia were cut, except the left metathoracic nerve 5 . This nerve was dissected through the coxa and into the femur to branch N5B1 close to the FCO. The ganglion, with some of its tracheal supply still attached, and the length of nerve 5 were then removed from the locust and secured on a Sylgard-coated dish in saline that barely covered its surface. The ends of the longitudinal tracheae were opened to the air. N5B1 was placed on the same pair of wire electrodes as above, which were then used solely for electrical stimulation. This preparation remained viable for about $2 \mathrm{hr}$.

In both preparations, the penetration of intracellular recording electrodes into the axons of FCO afferents was facilitated by prior treatment of the neural sheath with a $0.1 \%(\mathrm{w} / \mathrm{v})$ solution of Protease (Sigma type XIV) for 1-2 min. The afferents were penetrated in an anteroventral region of nerve 5 just at the point where it joins the metathoracic ganglion (see Fig. 1). The diameter of these afferents as they leave the organ ranges from 0.3 to $5.1 \mu \mathrm{m}$ (Matheson and Field, 1990). The more stable recordings were probably made from the larger-diameter fibers, but our sampling includes afferents with all known response properties. They could be identified in the intact preparation by their response to movements of the FCO apodeme, and by an orthodromic spike elicited by stimulation of N5B1. The latter test was the only means of identification in the isolated ganglion. In other experiments, identification was extended by intracellular labeling of the penetrated neurons to reveal their characteristic patterns of central branches, and by signal averaging, which shows that spikes evoked at the recording microelectrode propagate antidromically to the FCO (M. Burrows and T. Matheson, unpublished observations). Electrodes were used that had DC resistances of up to $80 \mathrm{M} \Omega$ when filled with $3 \mathrm{M}$ potassium acetate. The membrane potential of the afferent was controlled in either bridge- or current-clamp mode using an Axoclamp $2 \mathrm{~A}$ amplifier. For current clamp, the tips of the microelectrodes were coated with Sylgard and the saline kept to a minimum to reduce electrode capacitance. This method was used only in an isolated ganglion. The headstage voltage was monitored constantly on a separate oscilloscope to ensure complete settling at the end of each switching cycle ( $30 \%$ duty cycle). Switching rates of $5-6 \mathrm{kHz}$ were usually obtained. Data were filtered at $0.3-1 \mathrm{kHz}$.

Drugs could be applied to either preparation in two ways. First, bath application using an exchange valve mechanism (Holder and Sattelle, 1972) produced long (tens of minutes) access times to the central synapses because of the restrictions imposed by the sheath around the CNS. Second, pressure injection of drugs directly into the region of neuropil that contains the terminals of the FCO afferents produced effects that were seen in fractions of seconds. Before the electrode was inserted into the neuropil, the pressure and duration of the pulse for delivery were optimized under visual control by injection into a drop of mineral oil. The drugs used were $\gamma$-amino butyric acid (GABA), muscimol (5-aminomethyl-3-hydroxyisoxazole), bicuculline methiodide, and picrotoxin, all obtained from Sigma.

Data were captured on an eight-channel DAT recorder $(5 \mathrm{kHz}$ per channel) for subsequent analysis and display either on a digital oscilloscope and X-Y plotter, or on a Gould thermal array recorder. The results are based on recordings from $331 \mathrm{FCO}$ afferents in 48 locusts.

\section{Results}

Synaptic potentials in FCO afferents

Intracellular recordings from the axon of an FCO afferent close to the point where it enters the metathoracic ganglion reveal 

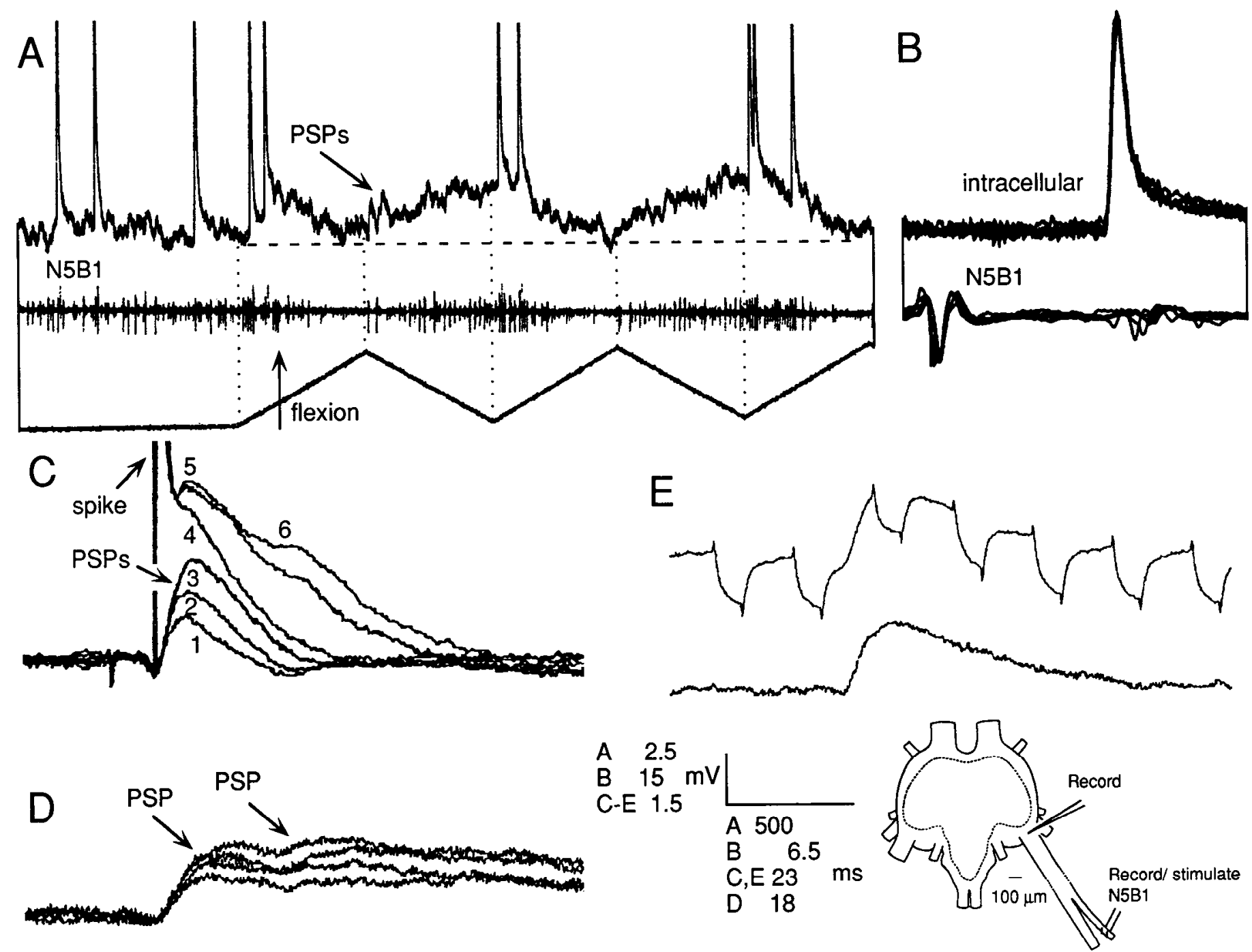

Figure 1. Synaptic potentials in an FCO afferent result from spikes in other FCO afferents. $A$, Movements of the FCO apodeme that simulate flexion (up) and extension (down) movements of the femoro-tibial joint evoke spikes in FCO afferents recorded extracellularly from N5B1. An intracellular recording from one of these afferents, held hyperpolarized by a steady current of $1.5 \mathrm{nA}$, shows that its spikes (peaks are clipped) are superimposed on depolarizing synaptic potentials, whose pattern reflects the imposed movement. The horizontal dashed line indicates the resting potential of the afferent and shows the depolarizations evoked by the synaptic potentials that result from movement of the FCO apodeme. $B$, The impaled afferent is identified by superimposing several sweeps triggered from its spike to reveal a correlated spike in N5B1 at the FCO. Other afferents are also active in the extracellular nerve recording. $C$, Increasing the intensity of a single electrical stimulus (marked by initial downward artifact) to N5B1 evokes PSPs of increasing amplitude (1-3). A spike (peak is clipped) is eventually evoked that has an inflection on its falling phase, indicating the continued presence of the PSP (4). Increasing the strength still further evokes a PSP of still larger amplitude (5) and finally an additional, later PSP (6), but no further spikes. The afferent is held hyperpolarized by $1.5 \mathrm{nA}$. The initial hyperpolarizing potential preceding the spike and PSPs is a field potential associated with the afferent volley that is evoked by the electrical stimulus. $D$, In another afferent electrical stimulation consistently evokes two PSPs. The increasing amplitudes of the PSPs correspond to increasing stimulus intensities. $E$, Constant-current hyperpolarizing pulses injected into the same afferent as in $C$ reveal a decrease in the resistance of its membrane during a PSP. The afferent was held hyperpolarized at about $-90 \mathrm{mV}$ where its current-voltage relationship is linear (see Fig. 2C). The top trace is an average of eight PSPs; the lower trace shows a single PSP. The diagram shows the metathoracic ganglion and position of the recording and stimulating electrodes.

both orthodromic spikes and depolarizing synaptic potentials in response to a movement of the FCO apodeme (Fig. 1A). In the example shown, the spikes in the afferent are superimposed on synaptic potentials whose pattern is related directly to the sequence of applied movements and to the pattern of spikes in the other FCO afferents. The impaled neuron can be identified as an FCO afferent either by signal averaging or by superimposing sweeps of the oscilloscope triggered from the intracellularly recorded spike to reveal a correlated, preceding spike in N5B1 near the FCO (Fig. 1B). The synaptic potentials and orthodromic spikes can also be evoked by electrical stimulation of N5B1 (Fig. 1C). In many of the afferents they can be evoked independently by appropriate manipulation of the electrical stimulus. For example, in Figure $1 C$ a single electrical stimulus of low intensity evokes only a PSP in the impaled afferent. This shows that at least some of the synaptic potentials are not generated by the spikes of the impaled afferent. Gradually increasing the strength of the stimulus evokes PSPs of larger amplitude. Eventually an orthodromic spike is initiated at the stimulating electrodes that is conducted toward the ganglion and is recorded as superimposed on the PSPs (Fig. 1C). This spike has an inflection on its falling phase that indicates the continuing presence of PSPs. Further increases in the stimulus intensity lead to an increase in the amplitude of the inflection on the falling phase 


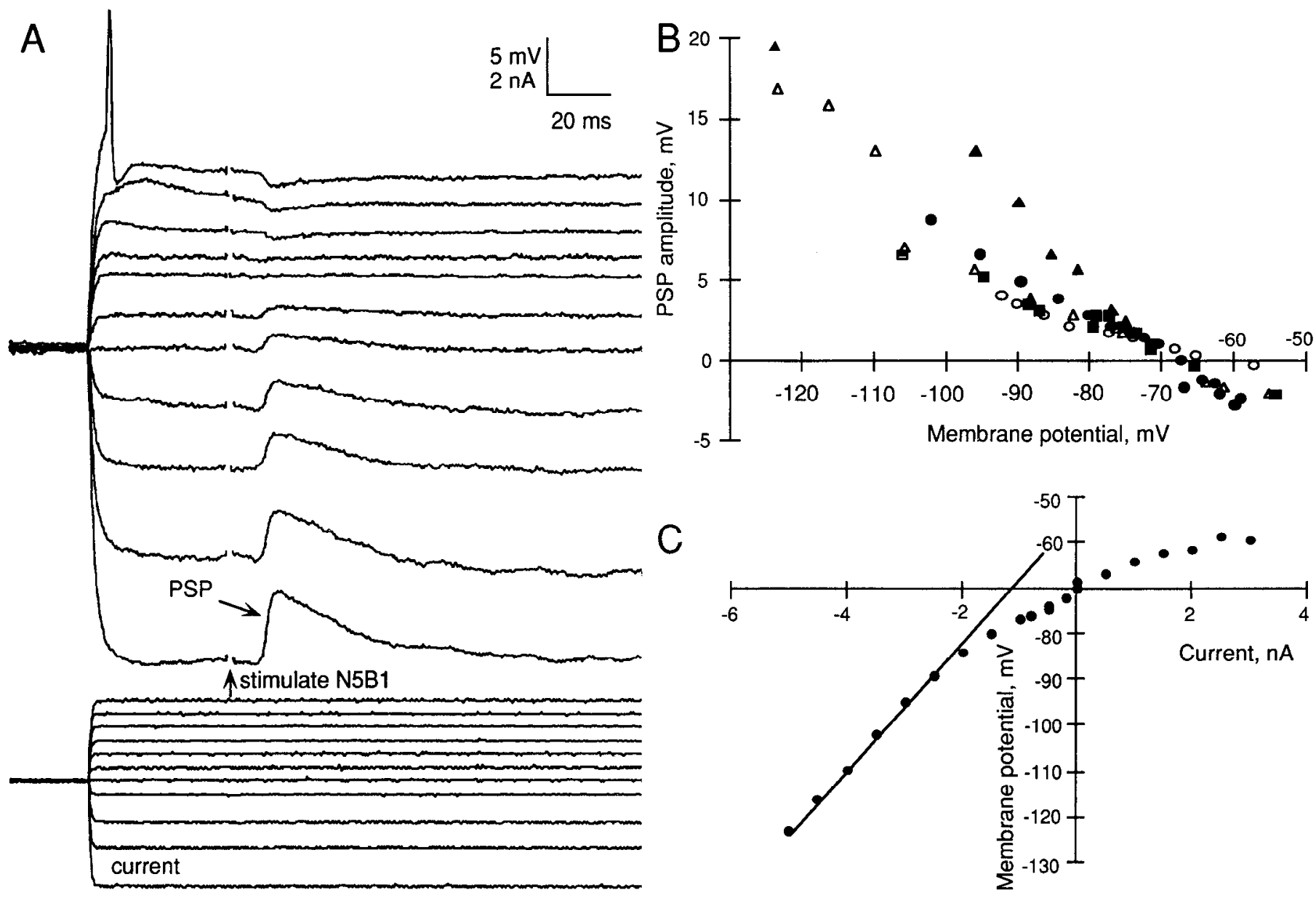

Figure 2. Reversal potential of the PSP in an affercnt. A, An afferent was current clamped in an isolated ganglion while a PSP was evoked by electrical stimulation of N5B1. Each trace is the average of eight sweeps. The PSP is depolarizing at the resting potential of $-75 \mathrm{mV}$. Depolarization of the afferent causes the PSP to reverse, while hyperpolarizing currents increase its amplitude. Note the outward rectification. $B$, Plot of the reversal potential of PSPs recorded in five afferents under current clamp in five locusts. The reversal potential of all was more positive than resting potential. $C$, Plot of the membrane potential of an afferent against applied current reveals outward rectification at potentials more positive than - $80 \mathrm{mV}$. The membrane potential was measured at steady state. The input resistance of the afferent is about $15 \mathrm{M} \Omega$ as measured from the slope of the linear region of the $I / V$ curve.

of the spike, and sometimes to a second, later inflection (Fig. 1C). In this particular afferent, the orthodromic spike and the PSP occur with the same latency, hut in other afferents the PSP can either precede or follow the start of the spike, presumably reflecting different conduction velocities of the spikes in different afferents. Typically a single electrical stimulus evokes just one PSP, but in some afferents increasing the stimulus intensity evokes a second PSP (Fig. $1 D$ ). In no afferents, however, did a single stimulus evoke two orthodromic spikes. This suggests that the PSPs are caused either by spikes in neurons other than the FCO afferents, or by afferents with different thresholds and markedly different conduction velocities.

The PSPs appear to be generated in the metathoracic ganglion. Removal of the FCO itself does not abolish the PSPs, though their frequency may be reduced, indicating that they are not events associated with mechano-transduction at the organ and simply conducted decrementally over $30 \mathrm{~mm}$ to the recording site. By contrast, if the recording microelectrode is moved distally along N5 so that it is farther from the metathoracic ganglion, then the PSPs that are recorded have smaller amplitudes. These observations suggest that the terminals of most FCO afferents receive synaptic inputs that can result from spikes in other afferents of the same organ. The pathways mediating the
PSPs are reliable, as is indicated by the consistency with which they can be evoked and the constancy of the latency from the stimulus. The amplitude of the PSPs is a graded, though apparently quantized, function of stimulus intensity, thus suggesting the existence of converging inputs from several neurons onto one afferent.

An evoked synaptic potential is associated with a large-conductance increase as revealed at the site of impalement by constant current, hyperpolarizing pulses (Fig. $1 E$ ). In some afferents, the PSP and the spike cannot be separated by adjusting the stimulus intensity so that the PSP is visible only as a positive inflection on the falling phase of the spike. A dependence of the PSP amplitude on the membrane potential of the afferent, and an associated conductance increase, can, however, still be shown. These observations suggest that the PSPs are caused by the release of transmitter at chemical synapses.

\section{Reversal potential of the PSP}

To determine the reversal potential of the PSPs, afferents were selected in which the PSPs could be evoked independently of the orthodromic spike by electrical stimulation of N5B1 in an isolated ganglion (Fig. 2). These afferents were then current clamped. At normal resting potential, the evoked PSP is de- 


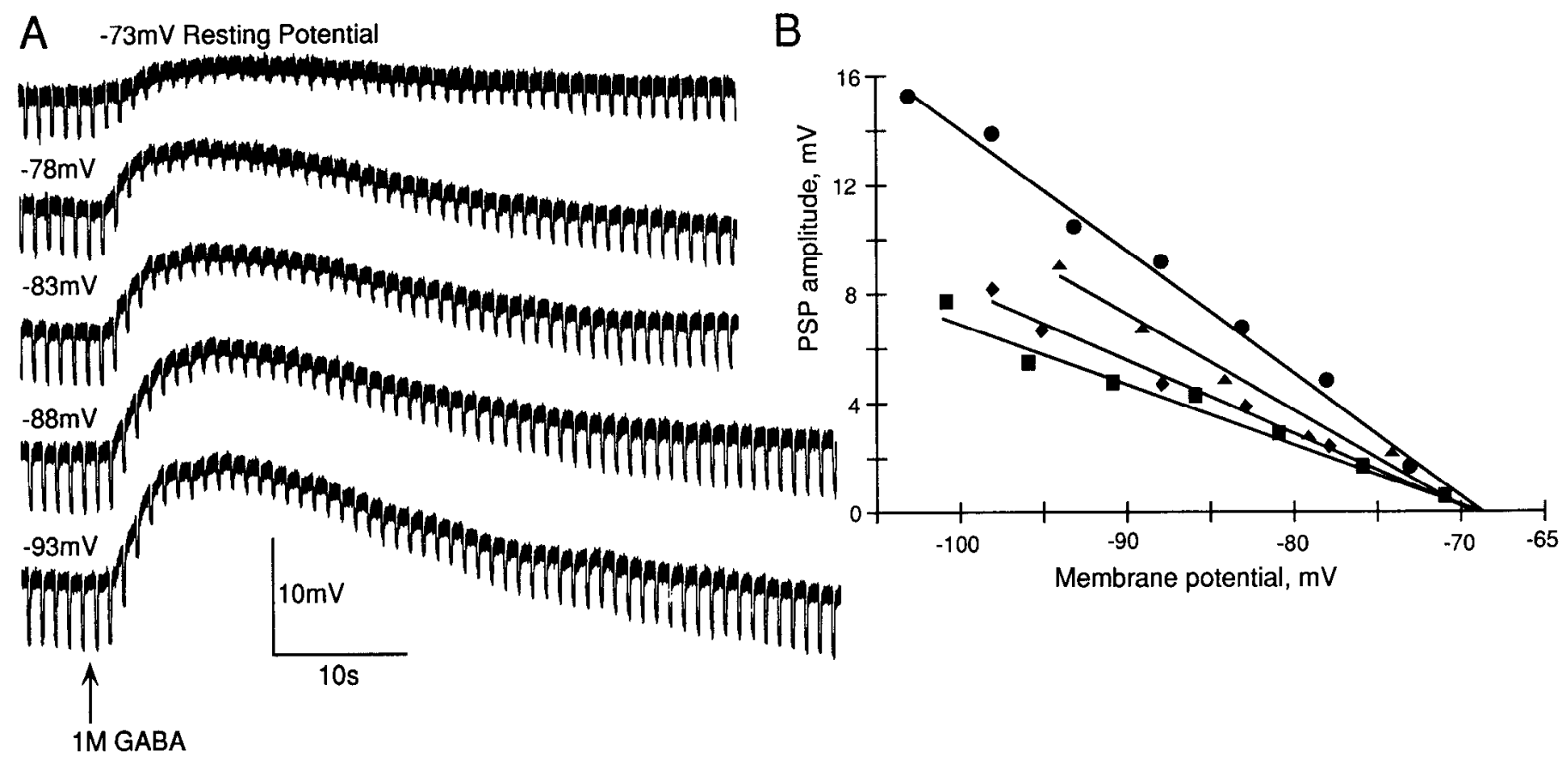

Figure 3. The PSPs in an afferent are mimicked by pulses of GABA injected into the neuropil. The afferent, which had a resting potential of -73 $\mathrm{mV}$, was current clamped in an isolated ganglion. $A$, A $50 \mathrm{msec}$ pulse of $1 \mathrm{~m}$ GABA was injected while the membrane was held at different potentials; $0.5 \mathrm{nA}$ pulses of hyperpolarizing current injected into the afferent reveal a marked decrease in resistance during the evoked depolarization. Increasing the membrane potential increases the amplitude of the evoked depolarization. Note that the resting input conductance is higher at the more depolarized potentials. $B$, Plot of the amplitude of the evoked GABA potential against membrane potential recorded in four current-clamped afferents from different locusts.

polarizing. Hyperpolarizing the afferent progressively increases the amplitude of the PSP (Fig. $2 A$ ). By contrast, progressive depolarization causes a decrease in the amplitude of the PSP, then reaches an apparent reversal potential, and finally results in a hyperpolarizing potential whose amplitude increases with further depolarization. Combining the data from five afferents in different locusts gives a reversal potential of $-68 \mathrm{mV}$ (Fig. $2 B)$, from an average resting potential of $-72 \mathrm{mV}( \pm 0.42 \mathrm{SE}$, $n=57$ afferents). The membrane of the afferent rectifies in an outward direction at potentials more positive than $-80 \mathrm{mV}$, but behaves linearly at more negative potentials (Fig. 2C).

\section{Evidence that GABA may meditale the PSPs}

Five lines of evidence suggest that the PSPs may be mediated by GABA.

\section{The PSPs and GABA-evoked potentials have the same reversal potential}

Injection of a pulse of 0.1 or $1 \mathrm{M} \mathrm{GABA}$ into the neuropil evokes a depolarization of approximately $2 \mathrm{mV}$ in an afferent at its normal resting potential (Fig. $3 A$ ). The rapidity and constancy of the onset of the depolarization in the afferent, and its repeatability, suggest that the GABA has a direct effect on the afferent membrane. Furthermore, the smooth change in membrane potential and the monotonic decay of the response suggest that parallel pathways involving other neurons in the ganglion are not activated. The potential is accompanied by an almost fourfold decrease in membrane resistance, as revealed by constant-current pulses (Fig. 3A). The duration of the evoked depolarization is related to the duration of the applied pulse and to the position of the electrode in the neuropil; with a $10-\mathrm{msec}-$ long pulse, the membrane returns to its original level after ap- proximately $20 \mathrm{sec}$, whereas a $50 \mathrm{msec}$ pulse produces an effect that lasts for $60 \mathrm{sec}$. As was seen for the PSP evoked by electrical stimulation, the GABA-evoked potential decreases in amplitude when the membrane potential of the afferent is depolarized, and is enhanced when the membrane is hyperpolarized. For example, at $20 \mathrm{mV}$ negative to rest, the amplitude of the evoked depolarization increases to $10 \mathrm{mV}$ (Fig. $3 \mathrm{~A}$ ). Plotting the peak amplitude of the depolarization cvoked by pulses of GABA against membrane potential shows that in four afferents in different locusts it reverses between -65 and $-70 \mathrm{mV}$ (Fig. $3 B$ ), the same potential as for the PSP evoked by stimulation of N5B1 (compare Figs. $2 B, 3 B$ ). Outward rectification of the afferent usually prevented an actual reversal of the potential.

The cell bodies of the chordotonal afferents show immunoreactivity to acetyliransferase (Lutz and Tyrer, 1988) and may therefore use $\mathrm{ACh}$ as a transmitter. In contrast to the responses to GABA, injecting $0.1 \mathrm{M}$ pulses of the ACh agonist carbachol into the neuropil evoked only a slow and small depolarization accompanied by only a $7-10 \%$ increase of conductance in an afferent at its normal membrane potential.

\section{GABA blocks the PSPS evoked by electrical stimulation}

GABA injected into the neuropil reduces the amplitude of PSPs evoked by electrical stimulation of N5B1 (Fig. 4). Repetitive stimulation at low frequency evokes PSPs of consistent amplitude superimposed on a background of other depolarizing PSPs. The pulse of GABA depolarizes the afferent and reduces the amplitude of both the evoked PSP and the background PSPs (Fig. $4 A$ ). An expanded time scale shows that the amplitude of the evoked PSP is reduced from $3.5 \mathrm{mV}$ to $0.5 \mathrm{mV}$ during the peak of the GABA-evoked depolarization and then gradually returns to its previous amplitude (Fig. $4 B$ ). The recovery of the 
stimulus-evoked PSP, however, occurs more slowly than the recovery of the membrane potential (Fig. $4 A$ ). The decrease in amplitude of the PSPs cannot, therefore, be due simply to a decrease in their driving force as the membrane is depolarized. In addition, a voltage-dependent mechansism should be strictly correlated with membrane potential. The PSPs would then have the same amplitude when the membrane has returned to its original level as at the start of the injection. The observed effects suggest that the pulse of GABA desensitizes receptors on the afferent membrane, and that the slow recovery in the amplitude of the PSP is due to recovery of these receptors.

\section{$G A B A$ blocks PSPs caused by movements of the FCO}

GABA injected into the neuropil also abolishes the PSPs that are evoked in an afferent by movements of the FCO apodeme (Fig. 5). A brief movement of the FCO apodeme repeated at intervals of $1.6 \mathrm{sec}$ produces a reliable and consistent pattern of PSPs in an afferent without evoking spikes in the afferent itself (Fig. 5A). When a pulse of GABA is injected into the neuropil, the afferent is depolarized and the response to the FCO movements is reduced. As the depolarization declines, the response to the $\mathrm{FCO}$ movements gradually recovers (Fig. 5). Throughout this period movements of the FCO apodeme continuc to evoke spikes in many afferents as indicated by the extracellular recording from N5B1 (Fig. 5). The background of PSPs is again affected by the GABA pulse in the same way as the evoked potentials, indicating that the majority of PSPs are caused by the same, or similar mechanisms.

The PSPS and the effects of $G A B A$ are mimicked by a $G A B A$ agonist

Injection of the GABA agonist muscimol into the neuropil causes a depolarization of an FCO afferent that is accompanied by a large decrease in the resistance of its membrane (Fig. 6 A). The evoked depolarization is reduced when the afferent is depolarized by a steady current and is accentuated when it is hyperpolarized, in the same way as for a GABA-evoked potential. Similarly, an injection of muscimol reduces the PSP evoked by electrical stimulation of N5B1 (Fig. 6B,C), the PSPs evoked by FCO movements, and the background PSPs. Muscimol therefore mimics all the effects produced by GABA.

\section{The PSPs are blocked reversibly by a GABA antagonist}

Bath application of $10^{-5} \mathrm{M}$ picrotoxin reduces the amplitude of the PSPs evoked by electrical stimulation of N5B1 (Fig. 7A). This method was used because focal injection into the neuropil failed to affect the amplitude of the PSPs. The effect with bath application takes at least $10 \mathrm{~min}$ to be fully expressed, presumably reflecting the time taken for the drug to reach the neuropil through the surrounding sheath of the ganglion. With these concentrations the block of the PSPs is never complete, but it is completely reversed when the picrotoxin is washed out (Fig. $7 B)$. With higher concentrations of picrotoxin $\left(10^{-4} \mathrm{M}\right.$ in Fig. $7 C$ ), the blockage of the PSPs is more complete but recovery is then incomplete, presumably because not all of the picrotoxin is removed from the ganglion. The picrotoxin also reversibly reduces the amplitude of the background PSPs to barely detectable levels (Fig. 7D).

Bicuculline, a powerful antagonist of $\mathrm{GABA}_{\mathrm{A}}$ receptors in vertebrates but effective at only some insect $\mathrm{GABA}$ receptors (Waldrop et al., 1987), was tested both by injection and by bath application. In only 1 of 10 trials, was the amplitude of a PSP

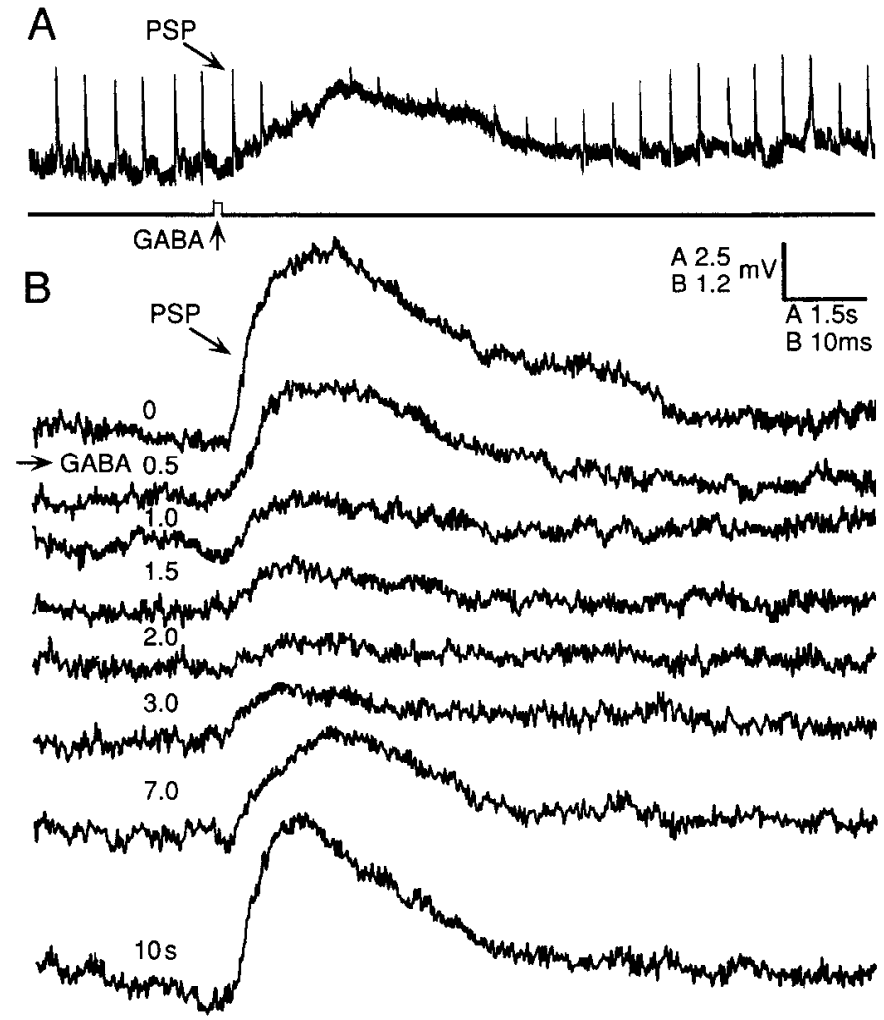

Figure 4. Synaptic potentials in an afferent evoked by electrical stimulation of $\mathrm{N} 5 \mathrm{~B} 1$ are reduced in amplitude by GABA injections into the neuropil. $A$, A $50 \mathrm{msec}$ pulse of 1 M GABA depolarizes the afferent, reduces the amplitude of the electrically evoked PSPs, and reduces the amplitude of the background PSPs. The recovery of the PSP is slower than the return of the membrane potential to its original level. $B$, Selected, electrically evoked PSPs from another injection of GABA showing, on an expanded time scale, the reduction in amplitude of the individual PSPs and their recovery. The afferent is held hyperpolarized by a steady current of $1.3 \mathrm{nA}$ from its resting potential of $-72 \mathrm{mV}$.

evoked by electrical stimulation reduced reversibly when a pulse of the drug was injected into the neuropil.

\section{PSPS and GABA potentials reduce the excitability of the afferents}

To test whether a PSP could change the excitability of an afferent, an electrical stimulus was delivered to N5B1 while a pulse of depolarizing current was injected into the afferent held at its resting potential (Fig. 8). The current pulse is $1.2-1.4$ times threshold for evoking spikes and by itself consistently evokes a spike. If, however, the current pulse is preceded by an evoked PSP, then the ability of the membrane to spike in response to the same current pulse is abolished and only a small graded response remains. The reduced excitability persists for some 100-130 msec and thereby considerably outlasts the conductance change associated with the PSP. As the period between the two events is lengthened, the amplitude of the graded active response increases, but spikes resume only when the interval is more than $100 \mathrm{msec}$ (Fig. 8).

The reduced excitability caused by a PSP could also be demonstrated when an afferent produced a burst of spikes on release from hyperpolarization (Fig. 9). The sequence of spikes could be interrupted by a single stimulus to N5B1, indicating that the evoked EPSP in the terminal leads to a temporary decrease in the excitability of the membrane. The period of silence evoked 
Figure 5. Synaptic potentials in an afferent evoked by movements of the FCO apodeme are affected by GABA injected into the neuropil. $A$, During repetitive movements of the apodeme representing a flexion (upward on third trace) of the tibia of $60^{\circ}$, a $50 \mathrm{msec}$ pulse of $1 \mathrm{M}$ GABA is injected. The afferent is depolarized, the movement evoked depolarizations, and the background synaptic potentials are reduced in amplitude. The afferent is held hyperpolarized by a steady current of $1.9 \mathrm{nA}$ from its resting potential of $-75 \mathrm{mV}$. $B$, Selected movements from the sequence in $A$ (indicated by the corresponding numbers) to show the detailed response of the afferent. The shifts in position of the top traces represent the true shifts in membrane potential that occur as a result of the pulse. The $\mathrm{sec}$ ond trace is an extracellular recording from N5B1 that shows the unchanged responses of the $\mathrm{FCO}$ afferents.

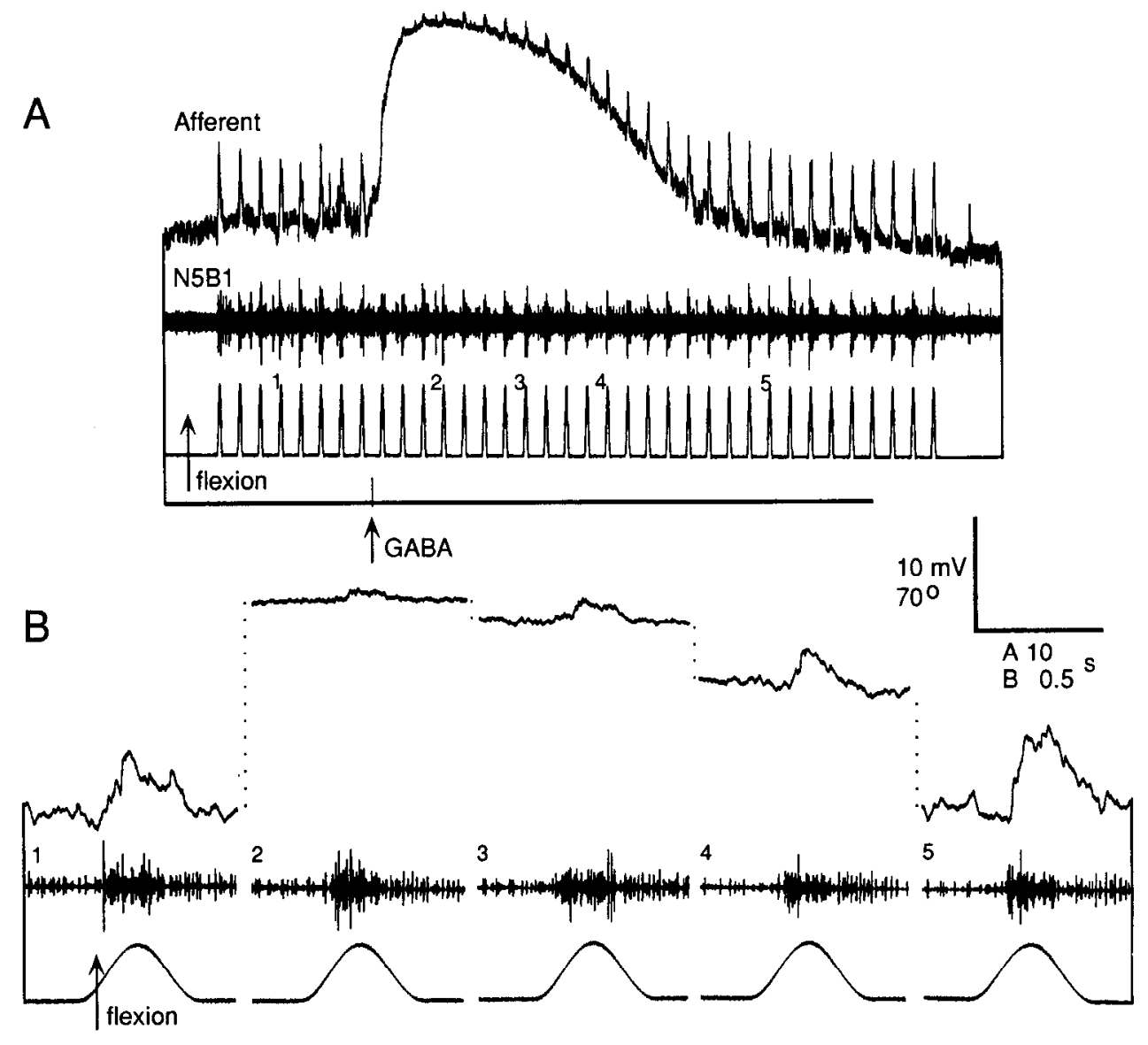

by a single PSP increases from 25 to $100 \mathrm{msec}$ as the frequency of spikes declines (Fig. 9B).

\section{Discussion}

Synaptic potentials in afferent terminals

Synaptic potentials are a consistent feature of intracellular recordings from sensory neurons of the femoral chordotonal organ. They occur spontaneously and can be evoked by movements of the FCO apodeme or by electrical stimulation of its nerve. A recording site where the axons enter the metathoracic ganglion was chosen because here they are bundled together so that the probability of successfully impaling these small neurons was somewhat enhanced. Here it is possible to record potentials of a few millivolts in amplitude, to detect the conductance changes that underlie them, and to reverse the potentials with current injected through the microelectrode. From the known morphology of these afferents (Burrows, 1987; Matheson 1992), and assuming that the synapses, like those on other insect afferents, are made onto the fine terminal branches (Watson and Pflüger, 1984), the electrodes are estimated to be within $200-600 \mu \mathrm{m}$ of synapses on the various branches.

\section{Properties of the afferent membrane}

The resting potential of the afferents averaged $-72 \mathrm{mV}$, and from potentials less than $-80 \mathrm{mV}$, the membrane showed strong outward rectification upon depolarization, a feature in common with the cercal afferents in the cockroach (Blagburn and Sattelle, 1987). The reversal potential of the PSPs averaged $-68 \mathrm{mV}$ and is therefore close to, but always more positive than, the resting potential. The potentials were thus always small but depolarizing at resting potential. Their reversal potential indicates, however, that they are depolarizing IPSPs. Indeed, temporal summation of these PSPs never evoked spikes. The PSPs are accompanied by an increase in the membrane conductance and a decrease in the excitability of the membrane that outlasts the measured conductance change, indicating the contribution of additional, but as yet unknown, mechanisms. These effects demonstrate that the PSPs change the excitability of the terminals and this may, in turn, alter the effectiveness of transmitter release from the afferent terminals onto interneurons and motor neurons that comprise the local circuits for the control of leg movements (Burrows, 1987, 1988; Burrows et al., 1988; Laurent and Burrows, 1988).

\section{Is GABA the transmitter at these synapses?}

GABA injected into the neuropil appears to act directly on the afferents for the following reasons. First, GABA is effective only if delivered to neuropil containing the terminals of the afferents. Second, the latency to the evoked depolarization is consistent for one injection site. Third, the evoked depolarization rises smoothly and decays monotonically, indicating only one contributing component. No later depolarizations were seen that would indicate longer pathways. This does not exclude parallel effects on other neurons, but only indicates that thcy do not appear to contribute to the depolarization of the afferents. Fourth, the duration of the depolarization is related to the duration of the applied pulse and thus to the amount of GABA that is delivered. Fifth, the application of GABA is accompanied by an increase in the conductance of the afferent membrane. Further attempts to prove the directness of the effects were not 


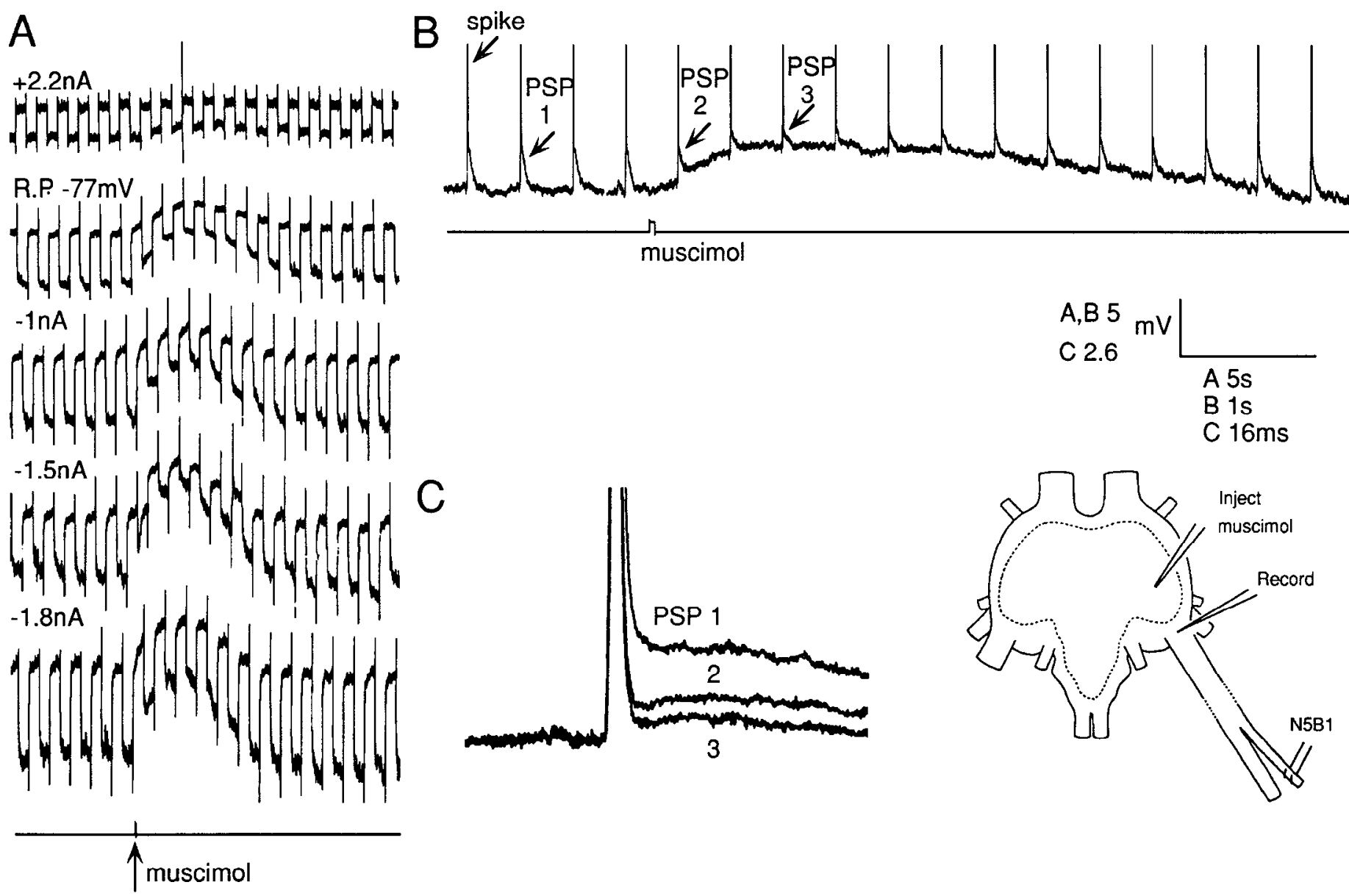

Figure 6. The effects of GABA on the membrane potential and on PSPs in an afferent are mimicked by muscimol. $A$, Pulses (40 msec) of $10^{-3}$ M muscimol were injected into the neuropil while the membrane potential was shifted from its resting value of $-77 \mathrm{mV}$ by steady currents injected through a bridge circuit. At resting potential, a depolarization is evoked that is reduced in amplitude by depolarizing and enhanced by hyperpolarizing currents. $B$, PSPs following the afferent spike evoked by electrical stimulation of N5B1 are reduced in amplitude during the muscimol pulse. The afferent is held hyperpolarized from its resting potential of $-77 \mathrm{mV}$ by a steady current of $1.5 \mathrm{nA}$. $C$, Three selected spikes and their accompanying PSPs (1-3) from the sequence in $B$ shown on an expanded time base. The start of the spikes are aligned but the peaks clipped. The diagram shows the position of the recording, injection, and stimulating electrodes.

successful, as the time taken to change the calcium levels in this compact neuropil exceeded the time that an intracellular recording could be maintained, and blocking spikes with TTX could not exclude the pervasive contribution of nonspiking neurons in these networks.

GABA appears to mimic all the effects of the PSPs on the afferents. Both the PSPs and the GABA-evoked potentials reverse at the same membrane potential (between -65 and -70 $\mathrm{mV}$ ). GABA blocks the electrically evoked PSPs, the PSPs evoked by movements of the FCO apodeme, and the spontaneously occurring PSPs. GABA and the PSPs both change the excitability of the membrane. The effects of GABA and the PSPs are also mimicked by muscimol, a GABA agonist. Finally, the PSPs are blocked reversibly by picrotoxin, suggesting that the receptor is associated with a chloride channel. Failure of bicuculline to block the PSPs in all but one experiment reflects a characteristic of most putative GABA receptors on central neurons of insects (Lees et al., 1987; Watson and Burrows, 1987; Benson, 1988) and crustaceans (Marder and Paupardin-Tritsch, 1978; Cazalets et al., 1987). In the moth antennal lobe, however, an inhibitory potential in projection interneurons, is blocked by both picrotoxin and bicuculline (Waldrop et al., 1987).

The GABAergic nature of the PSPs in the afferents is thus similar to vertebrates (Eccles et al., 1963; Davidoff, 1972; Nicoll and Alger, 1979) and other arthropods. In afferents of a crayfish chordotonal organ, for example, GABA evokes a depolarizing potential (El Manira and Clarac, 1991) but with a reversal potential some 15-40 mV above resting potential (Cattaert et al., 1992). In locusts the cercal afferents that receive synaptic inputs (Boyan, 1988) also have synapses onto them that show GABAlike immunoreactivity (Watson, 1990). In cercal afferents of the cockroach, the synaptic potentials are depolarizing (Blagburn and Sattelle, 1987), but bath application of GABA evokes a hyperpolarization (Hue and Callec, 1983). This discrepancy may be explained by the small voltage difference between reversal potential and resting potentials. Injection of GABA into the neuropil, however, produces a triphasic response in the interneurons postsynaptic to the afferents, in which the depolarizing component reverses at $-70 \mathrm{mV}$ and is blocked by picrotoxin (Hue, 1991). Similarly, potentials evoked by the application of GABA to the isolated somata of locust thoracic neurons reverse at around $-65 \mathrm{mV}$ (Lees et al., 1987). Both of these GABA 

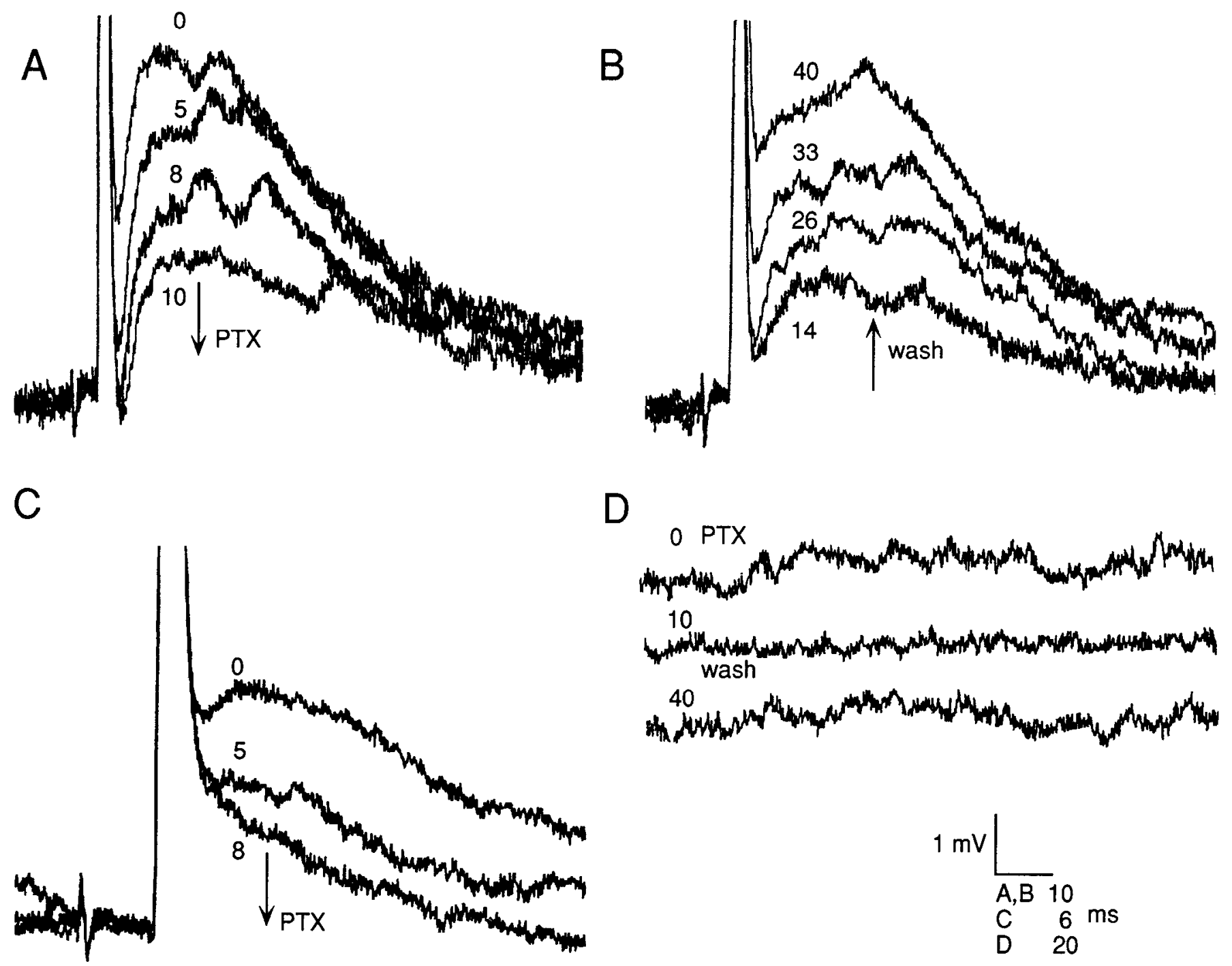

Figure 7. PSPs in an afferent are blocked by picrotoxin $(P T X) . A$ and $B$, Bath application of $10^{-5} \mathrm{M}$ picrotoxin causes a progressive reduction $(A)$ and complete recovery when washed out $(B)$ of the PSP that follows the spike. The numbers indicate the time in minutes after the application $(A)$ or washout $(B)$ of the picrotoxin. N5B1 was stimulated electrically. The afferent was hyperpolarized by a steady current of $1.5 \mathrm{nA}$ from its resting potential of $-72 \mathrm{mV}$. $C$, Picrotoxin at $10^{-4} \mathrm{M}$ causes more complete blockage of the PSPs in another afferent that was hyperpolarized by a steady current of $2.2 \mathrm{nA}$ from its resting potential. $D$, Background PSPs are also blocked, but then recover, when the picrotoxin (10 $\left.{ }^{-4} \mathrm{M}\right)$ is removed.

effects therefore have reversal potentials that are the same as those of the PSPs and GABA-evoked potentials described in this article.

\section{The pathways generating the PSPS}

Many of the synaptic potentials in an afferent are closely associated with spikes in other afferents from the same sense organ. Direct synaptic interactions between mechanosensory neurons are known (leech, Baylor and Nicholls, 1969; crab, Wildman and Cannone, 1991). In the crab, the interaction between the two neurons, most of whose information is coded in graded signals, should extend the dynamic range of the postsynaptic afferent neuron. In the locust FCO afferents, however, the PSPs do not appear to result from direct synaptic interactions between the afferents. Where evidence has been obtained for a reliable effect from one afferent to another, the latency between a spike in one and a synaptic potential in the other suggests the participation of an intervening central neuron (Burrows and Matheson, unpublished observations). This interpretation is further support- ed by the failure to mimic the naturally occurring PSPs by injecting an agonist of $\mathrm{ACh}$, the likely transmitter of mechanosensory neurons in insects (reviewed by Callec, 1974; Sattelle and Breer, 1990), into the neuropil close to the afferent terminals. Finally, insect mechanosensory neurons that have so far been examined do not show GABA immunoreactivity in their central terminals (Watson, 1990; Watson and England, 1991; Watson et al., 1991). We conclude that the PSPs evoked by individual FCO afferents in the terminals of another FCO afferent are caused indirectly by at least one layer of interposed interneurons. Several of these interneurons are expected to converge on each afferent. The pathway that activates these intermediate neurons must be reliable and involve high gains at the synapses, because single spikes in one afferent can consistently evoke PSPs in another.

\section{Functional implications}

This study shows that FCO afferents can lead to depolarizing IPSPs in the terminals of other afferents from the same sense 


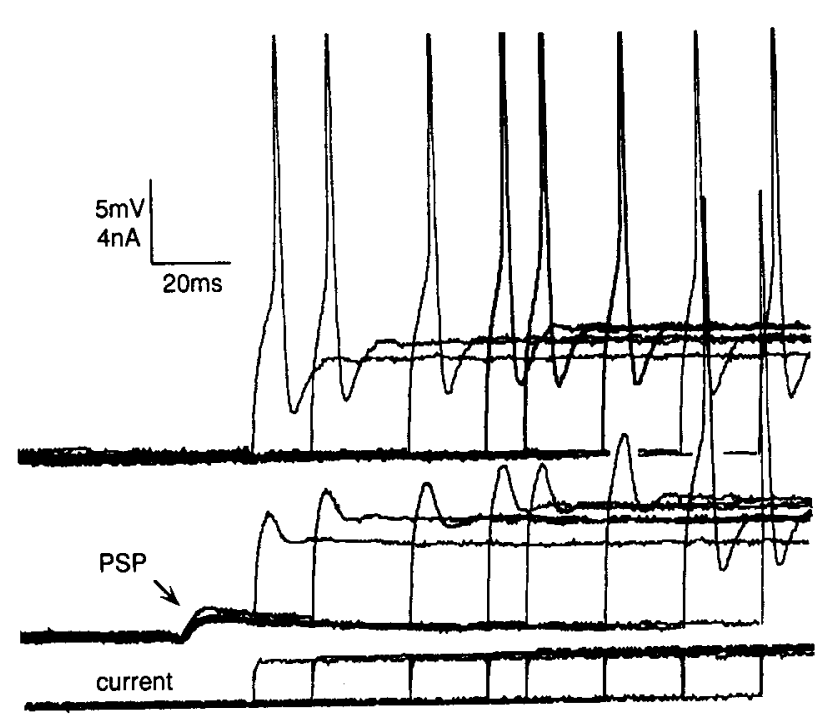

Figure 8. PSPs evoked by electrical stimulation of N5B1 reduce the excitability of an afferent. A stimulus was delivered to N5B1 and a pulse of depolarizing current was injected into an afferent (bottom trace) after different delays. When no PSP was evoked by the stimulus to N5BI, the pulse of current consistently evoked one spike (top trace). When a PSP preceded the pulse, only small active responses but no spikes were evoked until the interval exceeded $100 \mathrm{msec}$ (middle trace). The responses to 16 stimuli are superimposed.

organ. During certain movements, both the spikes and the synaptic potentials in some afferents are evoked by the same movement of the joint. The spikes in these afferents will therefore be superimposed on synaptic potentials resulting from spikes in other afferents that should reduce the excitability of their terminals. Their full postsynaptic effects will thus be expressed only if a spike invades the terminals either before or without the accompanying spikes of the other afferents that lead to the generation of the PSPs.

Depolarizing potentials known as primary afferent depolarizations (PAD) occur in the terminals of many afferents in different animals, both vertebrate and invertebrate, and have been particularly well characterized in the cat spinal cord (Frank and Fuortes, 1957; Eccles et al., 1961; Rudomin et al., 1983). They are often associated with spikes of afferents of the same or different modalities (Schmidt, 1971; Rudomin, 1990) or from neurons activated during a rhythmic motor pattern (Gossard et al., 1990, 1991). For example, flexor Ia afferents receive a polysynaptic depolarizing input from other flexor afferents (Brink et al., 1984; Rudomin, 1990). Cutaneous afferents, however, fail to evoke potentials in Ia terminals. The patterns of interactions are more complex with Ib, group II, and cutaneous afferents (Rudomin, 1990) and suggest that the last-order interneurons mediating PAD of spindle and tendon afferents are different (Rudomin et al., 1983, 1987; Harrison and Jankowska, 1985). For the muscle and tendon afferents, the PAD seems to act as a negative feedback mechanism leading to the inhibition of afferents of the same modality and thus regulating the fast segmental reflex loops (Schmidt, 1971). Such inputs are usually seen as a means of controlling the effectiveness of the afferent output synapses, but clear demonstrations of their effects are scarce (Blagburn and Sattelle, 1987). The interactions described here in the locust differ in that they can result from spikes in other afferents of the same organ. They could provide a mechanism for controlling the gain among the set of afferents that
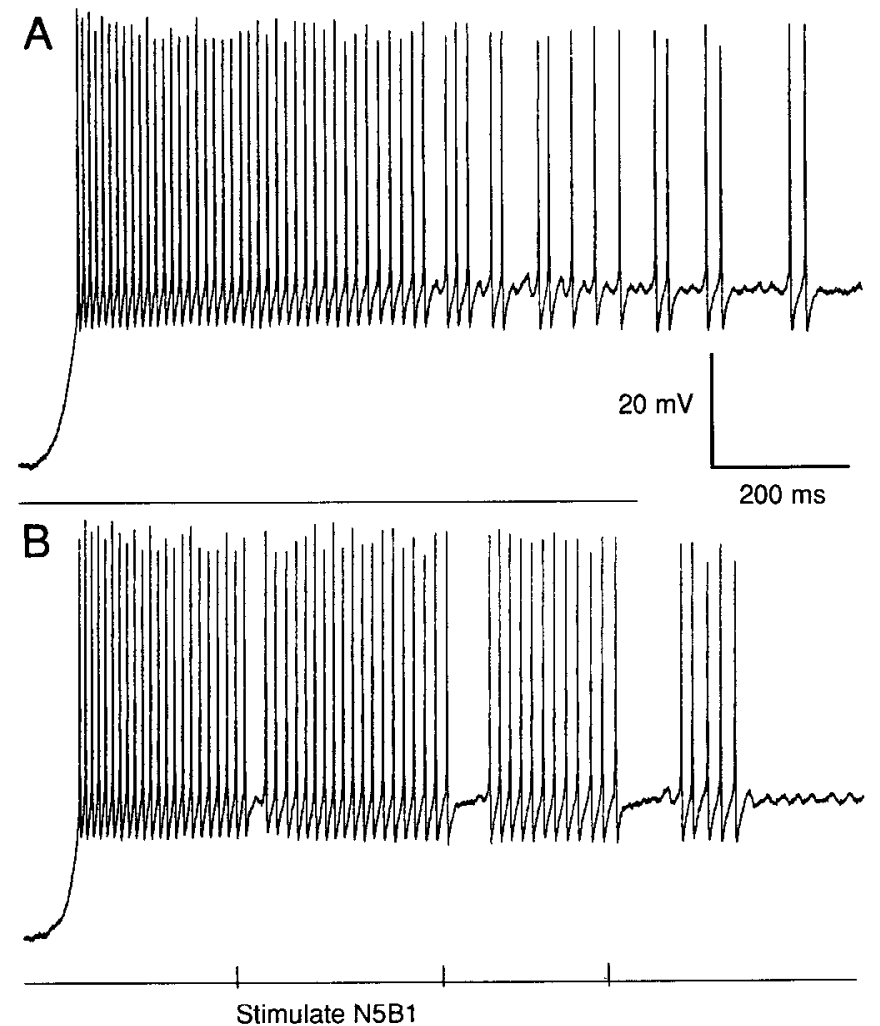

Figure 9. PSPs evoked by stimulation of N5B1 interrupt a sequence of spikes in an afferent. $A$, When released from hyperpolarization, the afferent produces a sequence of spikes. $B$, The afferent is again released from hyperpolarization, but this time three electrical stimuli are given to $\mathrm{N} 5 \mathrm{~B} 1$ that cause an orthodromic spike in the afferent that is followed by a PSP. Each stimulus interrupts the sequence of spikes for a progressively longer interval.

signal a particular movement of the joint. The gain of one afferent would be highest if it alone were activated by a movement, but would be downregulated in a graded fashion if other afferents were also recruited. This would avoid possible saturation of their effects when many afferents release transmitter simultaneously on a common target. This proposal can be tested by making simultaneous recordings from the afferent terminals and postsynaptic neurons while other afferents from the same organ are activated.

\section{References}

Altman JS, Shaw MK, Tyrer NM (1980) Input synapses onto a sensory neurone revealed by cobalt-electron microscopy. Brain Res 189:245250.

Bässler U (1976) Reversal of a reflex to a single motoneuron in the stick insect Carausius morosus. Biol Cybern 24:47-49.

Bässler U (1986) Afferent control of walking movements in the stick insect Cuniculina impigra. II. Reflex reversal and the release of the swing phase in the restrained foreleg. J Comp Physiol 158:351-362.

Baylor DA, Nicholls JG (1969) Chemical and electrical synaptic connections between cutaneous mechanoreceptor neurones in the nervous system of the leech. J Physiol (Lond) 203:591-609.

Benson JA (1988) Bicuculline blocks the response to acetylcholine and nicotine but not to muscarine or GABA in isolated insect neuronal somata. Brain Res 458:65-71.

Blagburn JM, Sattelle DB (1987) Presynaptic depolarization mediates presynaptic inhibition at a synapse between an identified mechanosensory neurone and giant interneurone 3 in the first instar cockroach, Periplaneta americana. J Exp Biol 127:135-157. 
Boyan GS (1988) Presynaptic inhibition of identified wind-sensitive afferents in the cercal system of the locust. J Neurosci 8:2748-2757.

Brink E, Jankowska E, Skoog B (1984) Convergence onto interneurons subserving primary afferent depolarisation of group I afferents. J Neurophysiol 51:432-449.

Burrows M (1987) Parallel processing of proprioceptive signals by spiking local interneurones and motor neurones in the locust. J Neurosci 7:1064-1080.

Burrows M (1988) Responses of spiking local interneurones in the locust to proprioceptive signals from the femoral chordotonal organ. J Comp Physiol 164:207-217.

Burrows M, Laurent GJ, Field LH (1988) Proprioceptive inputs to nonspiking local interneurones contribute to local reflexes of a locust hindleg. J Neurosci 8:3085-3093.

Büschges A (1989) Processing of sensory input from the femoral chordotonal organ by spiking interneurones of stick insects. J Exp Biol 144:81-111.

Callec JJ (1974) Synaptic transmision in the central nervous system of insects. In: Insect neurobiology (Treherne JE, ed), pp 119-185. New York: Elsevier.

Cattaert D, El Manira A, Marchand A, Clarac F (1990) Central control of the sensory afferent terminals from a leg chordotonal organ in crayfish in vitro preparation. Neurosci Lett 108:81-87.

Cattaert D, El Manira A, Clarac F (1992) Direct evidence for presynaptic inhibitory mechanisms in crayfish sensory afferents. J Neurophysiol 67:610-624.

Cazalets JR, Cournil I, Geffard M, Moulins M (1987) Suppression of oscillatory activity in crustacean pyloric neurons: implication of GABAergic inputs. J Neurosci 7:2884-2893.

Davidoff RA (1972) GABA antagonism and presynaptic inhibition in the frog spinal cord. Science 175:331-333.

Eccles JC, Eccles RM, Magni F (1961) Central inhibitory action attributable to presynaptic depolarization produced by muscle afferent volleys. J Physiol (Lond) 159:147-166.

Eccles JC, Schmidt R, Willis WD (1963) Pharmacological studies on presynaptic inhibition. J Physiol (Lond) 168:500-530.

El Manira A, Clarac F (1991) GABA-mediated presynaptic inhibition in crayfish primary afferents by non-A, non-B GABA receptors. Eur J Neurosci 3:1208-1218.

El Manira A, DiCaprio RA, Cattaert D, Clarac F (1991) Monosynaptic interjoint reflexes and their central modulation during fictive locomotion in crayfish. Eur J Neurosci 3:1219-1231.

Field LH, Burrows M (1982) Reflex effects of the femoral chordotonal organ upon leg motor neurones of the locust. J Exp Biol 101:265285.

Field LH, Rind FC (1981) A single insect chordotonal organ mediates inter- and intra-segmental leg reflexes. Comp Biochem Physiol 68A: 99-102.

Frank K, Fuortes MGF (1957) Presynaptic and postsynaptic inhibition of monosynaptic reflexes. Fed Proc 16:39-40.

Geisert B, Altner H (1974) Analysis of the sensory projection from the tarsal sensilla of the blowfly (Phormia teranovae Rob.-Desv., Diptera). Cell Tissue Res 150:249-259.

Gossard J-P, Cabelguen J-M, Rossignol S (1990) Phase-dependent modulation of primary afferent depolarization in single cutaneous primary afferents evoked by peripheral stimulation during fictive locomotion in the cat. Brain Res 537:14-23.

Gossard J-P, Cabelguen J-M, Rossignol S (1991) An intracellular study of muscle primary afferents during fictive locomotion in the cat. $J$ Neurophysiol 65:914-926.

Harrison PJ, Jankowska E (1985) Organization of input to the interneurones mediating group I non-reciprocal inhibition of motoneurones in the cat. J Physiol (Lond) 361:403-418.

Hofmann T, Koch UT (1985) Acceleration receptors in the femoral chordotonal organ of the stick insect, Cuniculina impigra. J Exp Biol 114:225-237.

Hofmann T, Koch UT, Bässler U (1985) Physiology of the femoral chordotonal organ in the stick insect, Cuniculina impigra. J Exp Biol 114:207-223.

Holder RED, Sattelle DB (1972) A multiway non-return valve for use in physiological experiments. I Physiol (Lond) 226:2-3P.

Hue B (1991) Functional assay for GABA receptor subtypes of a cockroach giant interneuron. Arch Insect Biochem Physiol 18:147157.

Hue B, Callec JJ (1983) Presynaptic inhibition in the cercal-afferent giant-interneurone synapses of the cockroach, Periplaneta americana L. J Insect Physiol 29:741-748.

Laurent G, Burrows M (1988) A population of ascending intersegmental interneurones in the locust with mechanosensory inputs from a hind leg. J Comp Neurol 275:1-12.

Lees G, Beadle DJ, Neumann R, Benson JA (1987) Responses to GABA by isolated neuronal somata: pharmacology and modulation by a benzodiazepine and a barbiturate. Brain Res 401:267-278.

Levine RB, Murphey RK (1980) Pre- and postsynaptic inhibition of identified giant interneurones in cricket (Acheta domesticus). J Comp Physiol 135:269-282.

Lutz EM, Tyrer NM (1988) Immunohistochemical localization of serotonin and choline acetyltransferase in sensory neurones of the locust. J Comp Neurol 267:335-342.

Marder E, Paupardin-Tritsch D (1978) The pharmacological properties of some crustacean neuronal acetylcholine, gamma aminobutyric acid, and L-glutamate responses. J Physiol (Lond) 280:213-236.

Matheson T (1992) Morphology of the central projections of physiologically characterised neurones from the locust metathoracic femoral chordotonal organ. J Comp Physiol 170:101-120.

Matheson T (1991) Morphology of the central projections of physiologically neurones from the locust metathoracic femoral chordotonal organ. J Comp Physiol 170:101-120.

Matheson T, Field LH (1990) Innervation of the metathoracic femoral chordotonal organ of Locusta migratoria. Cell Tissue Res 259:551560.

Nicoll RA, Alger BE (1979) Presynaptic inhibition: transmitter and ionic mechanisms. Int Rev Neurobiol 21:217-258.

Rudomin P (1990) Presynaptic control of synaptic effectiveness of muscle spindle and tendon organ afferents in the mammalian spinal cord. In: The segmental motor system (Binder MD, Mendell LM, eds), pp 349-380. New York: Oxford UP.

Rudomin P, Jimenez I, Solodkin M, Duenas S (1983) Sites of action of segmental and descending control of transmission on pathways mediating PAD of Ia- and $\mathrm{Ib}$-afferent fibers in cal spinal cord. $\mathrm{J}$ Neurophysiol 50:743-769.

Rudomin P, Solodkin M, Jimenez I (1987) Synaptic potentials of primary afferent fibers and motoncurons evoked by single intermediate nucleus interneurons in the cat spinal cord. J Neurophysiol 57: 1288-1313.

Sattelle DB, Breer H (1990) Cholinergic nerve terminals in the central nervous system of insects. J Neuroendocrinol 2:241-256.

Schmidt RF (1971) Presynaptic inhibition in the vertebrate central nervous system. Ergeb Physiol Biol Chem Exp Pharmakol 63:20-101.

Schmitz J, Dean J, Kittman R (1991) Central projections of leg sense organs in the stick insect Carausius morosus. Zoomorphology 111: 19-33.

Sillar KT (1989) Synaptic modulation of cutaneous pathways in the vertebrate spinal cord. Semin Neurosci 1:45-54.

Sillar KT, Roberts A (1988) A neuronal mechanism for sensory gating during locomotion in a vertebrate. Nature 331:262-265.

Sillar KT, Skorupski P (1986) Central input to primary afferent neurones in crayfish, Pacifastacus leniusculus, is correlated with rhythmic output of thoracic ganglia. J Neurophysiol 55:678-688.

Usherwood PNR, Runion HI, Campbell JI (1968) Structure and physiology of a chordotonal organ in the locust leg. J Exp Biol 48:305323 .

Waldrop B, Christensen TA, Hildebrand JG (1987) GABA-mediated synaptic inhibition of projection neurons in the antennal lobes of the sphinx moth, Manduca sexta. J Comp Physiol 161:23-32.

Watson AHD (1990) Ultrastructural evidence for GABAergic inputs onto cercal afferents in the locust (Locusta migratoria). J Exp Biol 148:509-515.

Watson AHD, Burrows M (1987) Immunocytochemical and pharmacological evidence for GABAergic spiking local interneurones in the locust. J Neurosci 7:1741-1751.

Watson AHD, England RCD (1991) The distribution of and interactions between GABA-immunoreactive and non-immunoreactive processes presynaptic to afferents from campaniform sensilla on the trochanter of the locust leg. Cell Tissue Res 266:331-341.

Watson AHD, Pflüger HJ (1984) The ultrastructure of prosternal sensory hair afferents within the locust central nervous system. Neuroscience 11:269-279.

Watson AHD, Storm-Mathisen J, Ottersen OP (1991) GABA and glutamate-like immunoreactivity in processes presynaptic to afferents 
from hair plates on the proximal joints of the locust leg. J Neurocytol 20:796-809.

Wildman MH, Cannone AJ (1991) Interaction between afferent neurones in a crab muscle receptor organ. Brain Res 565:175-178.

Zill SN (1985a) Plasticity and proprioception in insects. I. Responses and cellular properties of individual receptors of the locust metathoracic femoral chordotonal organ. J Exp Biol 116:435-461.

Zill SN (1985b) Plasticity and proprioception in insects. II. Modes of reflex action of the locust metathoracic femoral chordotonal organ. J Exp Biol 116:463-480. 